\title{
The Synergic Activity of Eucalyptus Leaf Oil and Silver Nanoparticles Against Some Pathogenic Bacteria
}

\author{
Maryam Asghar Heydari, ${ }^{1}$ Masoud Mobini, ${ }^{1}$ and Mohammad Salehi ${ }^{2,3,}$ \\ ${ }^{1}$ MS.c, Young Researchers and Elites Club, Tonekabon Branch, Islamic Azad University, Tonekabon, Iran \\ ${ }^{2}$ Blood Borne Infections Research Center, Academic Center for Education, Culture and Research (ACECR), Razavi Khorasan Branch, Mashhad, Iran \\ ${ }^{3}$ Medical Diagnostic Laboratory of Neyshabour, Center of Medical, Pathological and Genetic Diagnostic Services, Iranian Academic Center for Education, Culture and \\ Research (ACECR), Mashhad Branch, Mashhad, IR Iran \\ "Corresponding author: Mohammad Salehi, Msc, Blood Borne Infections Research Center, Academic Center for Education, Culture and Research (ACECR), Razavi Khorasan \\ Branch, Mashhad, Iran. Tel: +98-9358428423, Fax: +98-5143337042, E-mail: mohammadsalehi73@gmail.com
}

Received 2016 July 26; Revised 2016 January 05; Accepted 2016 November 08.

\begin{abstract}
Background: Notwithstanding the current advances in the drug discovery and the pharmaceutical biotechnology, the bacterial infectious diseases are still one of the biggest health concerns worldwide. Also, the new therapeutic methods are urgently required due to the increasing resistance to antimicrobial agents.

Objectives: The current study aimed at investigating the synergic effect of eucalyptus leaf oil and silver nanoparticles (Ag NPs) on Escherichia coli H7:O157, Escherichia coli, methicillin-resistant Staphylococcus aureus (MRSA), Salmonella enterica, and Bacillus subtilis. Methods: The current experimental study was performed in Islamic Azad University, Iran. The disc diffusion method, well diffusion method, and broth dilution assay were used in the current study.

Results: Results showed that none of the drugs affected the bacteria by disk diffusion method. In broth dilution method, E. coli O157:H7, E. coli, MRSA, and S. enterica showed the same susceptibility and B. subtilis showed more susceptibility to the combined agents.

Conclusions: The current study showed the synergic effect of Ag NPs $1.5 \mathrm{ppm}$ plus eucalyptus leaf oil on the growth inhibition of $E$. coli $\mathrm{O} 157: \mathrm{H7}$, E. coli, MRSA, S. enteric, and B. subtilis. The combined drug showed more efficiency; lower dose of each medicine in the combinatory form decreased the toxicity in the treatment of infections caused by these bacteria.
\end{abstract}

Keywords: Antimicrobial Synergic Activity, Ag NPs, Essential Oil, Eucalyptus, Minimal Inhibitory Concentration

\section{Background}

Bacteria are known as the cause of various human diseases from the late 1800 s (1). Notwithstanding the current advances in the drug discovery and the pharmaceutical biotechnology, the bacterial-induced infectious diseases are still one of the biggest health concerns worldwide, affecting millions of people every year (2).

Antimicrobial drugs saved millions of patients with chronic infections (1). Antimicrobial agents, epithet miraculous medications are the optimism of medical community in the past, but recent evidence indicated their strong restriction (3-7).

It should be mentioned that, bacteria evolve a variety of mechanisms of resistance to antibiotics. Hence, it is a great challenge to treat the infections caused by bacteria (8-11). It is clear that over the marketing of a new compound, typically the resistance is observed from 1 to 3 years (12-14). Until 2010, the care costs of resistant pathogens were 5 billion \$US per year (12), which is expected to rise. On the other hand, the major pharmaceutical corporations are losing appeal in the research and development of an- tibiotics. That is why such drugs are not quite rewarding in terms of the long-term benefits in comparison with medications used to treat chronic infections demanding the long therapy periods $(15,16)$. The development is expensive, time-consuming, risky, and unappealing due to the too short lifecycle of antibiotics (due to bacterial resistance) (15). The pipeline of new medications based on antimicrobials is being dried significantly. All in all, it is clear that the steady increase in the resistance of bacteria to antibiotics, coupled with a significant decrease in the confirmed antibacterial agents in the last decades is creating a great concern worldwide, and bacterial infections represent one of the major healthcare threats (13).

Due to the antimicrobial resistance, infectious diseases are one of the major health care challenges worldwide. Furthermore, disadvantages of conventional antimicrobial agents are the developing multidrug resistance and adverse side effects. Resistance to the drugs enforces the administration of high antibiotic doses, which in turn cause unbearable toxicity. This encourages the development of alternative approaches to treat bacterial diseases 
(17). It seems that looking for a new strategy for this problem is necessary.

The high surface area to volume ratio of nanoparticles (NP) results in the development of new properties of NPs that differ from bulk properties (18). There is evidence that Ag NPs can directly harm membranes of bacteria, silver nanomaterials seem to exert the bactericidal activity significantly by the continuous release of silver ions (alone or in combination), by an increase in the permeability of the membrane, loss of the proton motive force, the induction of deenergization of cells and efflux pumps of phosphate, leakage of the cellular content, and DNA replication disruption (19).

The NPs offer improved properties to organic antibacterial agents (18). It is shown that Ag NPs have synergic activities with antibiotics such as kanamycin, ampicillin, chloramphenicol, and erythromycin against grampositive and gram-negative bacteria. The combination of Ag NP with organic antibacterial agents has effective antibacterial activity (20). In other studies, the NPs offered improved properties to essential oils; Scandorieiro et al. showed oregano essential oil plus Ag NPs had synergic effect against all 3 extended spectrum beta-lactamase (ESBL)producing E. coli and this combination had bactericidal activity (21). The antibacterial activity of the eucalyptus oil was shown in different studies (22-26).

\section{Objectives}

The current study aimed at evaluating antibacterial activity of double drug combination including eucalyptus leaf oil and Ag NPs against some pathogenic bacteria.

\section{Methods}

\subsection{Preparing the Eucalyptus Oil}

The fresh leaf of eucalyptus were gathered from Tonekabon jungles, Mazandaran, Iran, and identified as Eucalyptus camaldulensis by the Islamic Azad University herbarium. Leaf was dried in dark shade, and then, milled. To prepare the oil extract, Clevenger apparatus was used. Then, $10 \mathrm{~g}$ of leaf was added to the balloon apparatus and 1 liter water was poured. After 4 hours, the extracted oil was poured in a dark bottle, and transferred to a refrigerator. The dimethyl sulfoxide (DMSO) was used to prepare different concentrations of oil and as negative control; 0.1 $\mathrm{mg} / \mathrm{mL}$ of the essential oil was prepared as stock.

\subsection{Strains and Microbial Suspension}

The MRSA ATCC 33591, E. coli O157:H7 ATCC 33150, E. coli PTCC 1399, S. enterica PTCC 1709, and B. subtilis PTCC 1156 were provided from Iranian research organization for science and technology (IROST). After testing all microorganisms, the suspensions were prepared according to $0.5 \mathrm{Mc}$ Farland.

\subsection{Preparing Ag NPS}

The Ag NPs (4000 ppm) were provided by Iranian Pishgaman Nonomaterial Company (Mashhad). The sizes of NPs were $20 \mathrm{~nm}$ and spherical.

\subsection{Disk Diffusion Assay}

Ten milliliters of microbial suspension was added to Muller-Hinton agar medium. Six disks containing 100, 50, 25, 12.5, 6.25 and $3.12 \mathrm{mg} / \mathrm{mL}$ oil, NPs, and the combined drug were placed on each plate. After incubation for 24 hours at $37^{\circ} \mathrm{C}$, the growth inhibition zones were measured. This test was repeated 3 times and finally the average was taken into account (27).

\subsection{Macrodilution Assay}

The minimal inhibitory concentration (MIC) values of both antimicrobials were determined by broth macrodilution method according to the clinical and laboratory standards institute (CLSI) guidelines 2012, with necessary modifications (28). Then, the concentrations of 100, 50, 25, 6.25, and $3.12 \mathrm{mg} / \mathrm{mL}$ of essential oil and the concentrations of $100,50,25,12.5,6.25$, and 1.5 ppm of Ag NPs were obtained. One hundred milliliters of microbial suspensions $108 \mathrm{CFU}$ $\mathrm{mL}^{-1}$ were added to Muller-Hinton broth, which contained different amounts of oil, Ag NPs, and the combined drug. After incubation for 24 hours at $37^{\circ} \mathrm{C}$, the MICs were determined. To determine minimal bactericidal concentration (MBC), $10 \mathrm{~mL}$ of suspensions were cultured on MullerHinton agar. After incubation, the MBCs were determined.

\subsection{Synergic Effect Assay}

After determining the MIC and MBC, in order to determine the synergic effect, the amounts of 2 folds, equal, half, and quarter of oil MIC were tested along with silver nanoparticle MIC (as constant).

\section{Results}

Results showed that the eucalyptus oil, Ag NPs, and a combination of both of them had no effect on the growth of the studied bacteria based on the disk diffusion method. The MIC and MBC of eucalyptus oil, Ag NPs, and a combination of both drugs against all strains of MRSA, E. coli 
O157:H7, E. coli, S. enterica, and B. subtilis are shown in Tables 1 to 7. The MIC and MBC values of eucalyptus oil against all strains were observed in the range of 12.5 to $25 \mathrm{mg} / \mathrm{mL}$ and 25 to 50, respectively (Table 1 ). These amounts for Ag NPs were 3.12 and 6.25 ppm, respectively (Table 2). Regarding the combinations, these amounts were in the range of 6.25 to $12.5 \mathrm{mg} / \mathrm{mL}$ with $1.5 \mathrm{ppm}$ Ag NPs (Tables 3 to 7 ).

\section{Discussion}

According to the current study results, the synergistic effect of eucalyptus leaf oil and Ag NPs were acceptable. As it can be observed, fewer doses were used in the combined drug, compared with the doses used in the noncombinatory form. Escherichia coli O157:H7, E. coli, MRSA, and $S$. enterica showed the same susceptibility, but $B$. subtilis showed more susceptibility to the combined drug.

Some studies confirmed the claim that some organic matters have synergistic effects alongside the NPs. Mirzaei et al. evaluated the antimicrobial effect of plant peptide MBP-1 and Ag NPs, along with their synergistic effect on skin infection caused by Pseudomonas aeruginosa. Their results showed that the MIC and MBC of MBP-1 plus Ag NPs on P. aeruginosa were $400 \mu \mathrm{g} / \mathrm{mL}$ plus $1.56 \mathrm{ppm}$ and $500 \mu \mathrm{g} / \mathrm{mL}$ plus 3.125 ppm, respectively (29).

Sharifi-Rad et al. reported that when allicin and Ag NPs were used in combination exhibited a synergistic activity in such a way that the MIC of allicin plus Ag NPs on MRSA were $0.4 \mathrm{mg} / \mathrm{mL}$ plus $1.1 \mathrm{ppm}$, respectively(30). These amounts in the current study results were $6.25 \mathrm{mg} / \mathrm{mL}$ plus 1.5 ppm, respectively. Then, allicin has more antimicrobial activity compared with eucalyptus oil against MRSA.

Naghsh et al. investigated the effect of eucalyptus plus Ag NPs as a new combination to inhibit the growth of $E$. coli. The result showed that the eucalyptus plus Ag NPs had maximum inhibitory effect on the growth of E. coli 1 day after the treatment. The results of this study suggested that the Ag NPs in combination with eucalyptus oil can be helpful to treat bacterial infections (31). The current study results indicated that the MIC and MBC of the combined drug for $E$. coli were $6.25 \mathrm{mg} / \mathrm{mL}$ plus $1.5 \mathrm{ppm} \mathrm{Ag} \mathrm{NPs} \mathrm{and} 12.5$ $\mathrm{mg} / \mathrm{mL}$ plus $1.5 \mathrm{ppm}$ Ag NPs, respectively.

Comparison of alcoholic extract of eucalyptus plus Ag NPs as a new nanocomposite to inhibit the growth of Aspergillus niger were investigated by Naghsh et al. Their results showed that the number of $A$. niger colonies decreased dramatically $(\mathrm{P}<0.01)$ in $12.5 \mathrm{ppm}$ of Ag NPseucalyptus 24 days after incubation (32).

Carbon complex silver (SCCs) with different formulations in some types including micelles and NPs have efficient toxicity against clinically important pathogens such as Klebsiella pneumoniae, MRSA, Burkholderia cepacia, multidrug-resistant Acinetobacter baumannii, and P. aeruginosa in the range of 0.5 to $90 \mathrm{mg} / \mathrm{L}$ (33).

Scandorieiro et al. showed that oregano essential oil plus Ag NPs had synergic effect against all 3 ESBL-producing E. coli and this combination also showed bactericidal activity (21).

Sheikholeslami et al. demonstrated that Ag NPs had synergic effects with Zataria multiflora essential oil and methanolic extract against some pathogenic bacteria; their results indicated that the MIC and MBC values of Ag NPs against Staphylococcus aureus, MRSA, Staphylococcus epidermidis, and P. aeruginosa were in the range of 15.6 to $500 \mu \mathrm{g} / \mathrm{mL}$. These values for the essential oil and plant extract were in the range of 1.56 to $100 \mathrm{mg} / \mathrm{mL}$ (34).

The shape, size, and controlled disparity of NPs play an important role in the determination of the properties attributed to their applications in the area of biomedicine (2, 35). Martinez-Castanon et al. noticed that the antibacterial activity of NPs varied when their sizes decreased (36).

There are a lot of other reports on the antibacterial effects of various NPs, but some reports were contradictory (37-40). These reports suggest that NPs toxicity mechanisms are exceedingly complicated and depend on various factors such as composition, surface modification, intrinsic properties, and the bacterial species.

The precise mechanisms of NP toxicity toward various bacteria are not completely understood. NPs are capable of binding to the membrane of the bacteria by means of the electrostatic interaction and interrupt the integrity of the bacterial membrane (41). Nanotoxicity typically triggered the oxidative stress induction by free radical formation after administering NPs $(42,43)$.

In conclusion, the current study results confirmed that 1.5 ppm Ag NPs plus eucalyptus leaf oil had synergic effect on inhibiting the growth of E. coli O157:H7, E. coli, MRSA, S. enterica, and B. subtilis. The combined therapy was more effective while lower doses of medicines were used and subsequently the toxicity of the medicine was decreased. The findings of the current study suggested that Ag NPs plus eucalyptus leaf oil can be a good alternative to treat some bacterial diseases.

\section{Acknowledgments}

Authors are very thankful to research deputy of Islamic Azad University for supporting the project.

\section{Footnotes}

Authors' Contribution: None declared. 
Table 1. The MIC and MBC of Eucalyptus Leaf Oil Against Some Bacterial Patogens

\begin{tabular}{|c|c|c|c|c|c|c|c|}
\hline Strain & MIC/MBC & 100 & 50 & 25 & 12.5 & 6.25 & 3.12 \\
\hline \multirow{2}{*}{ Escherichia coli 0157: H7 } & MIC & - & - & - & - & + & + \\
\hline & MBC & - & - & - & + & + & + \\
\hline \multirow{2}{*}{ E. coli } & MIC & - & - & - & - & + & + \\
\hline & MBC & - & - & - & + & + & + \\
\hline \multirow{2}{*}{ MRSA } & MIC & - & - & - & - & + & + \\
\hline & $\mathrm{MBC}$ & - & - & - & + & + & + \\
\hline \multirow{2}{*}{ Salmonella enterica } & MIC & - & - & - & - & + & + \\
\hline & MBC & - & - & - & + & + & + \\
\hline \multirow{2}{*}{ Bacillus subtilis } & MIC & - & - & - & + & + & + \\
\hline & MBC & - & - & + & + & + & + \\
\hline
\end{tabular}

Abbreviations: MRSA, methicillin-resistant Staphylococcus aureus, +, microorganism growth; -, without microorganism growth.

Table 2. The MIC and MBC of Silver Nanoparticles Against Some Bacterial Patogens

\begin{tabular}{|c|c|c|c|c|c|c|c|c|}
\hline Strain & MIC/MBC & 100 & 50 & 25 & 12.5 & 6.25 & 3.12 & 1.5 \\
\hline \multirow{2}{*}{ Escherichia coli $0157: \mathrm{H} 7$} & MIC & - & - & - & - & - & - & + \\
\hline & $\mathrm{MBC}$ & - & - & - & - & - & + & + \\
\hline \multirow{2}{*}{ E. coli } & MIC & - & - & - & - & - & - & + \\
\hline & $\mathrm{MBC}$ & - & - & - & - & - & + & + \\
\hline \multirow{2}{*}{ MRSA } & MIC & - & - & - & - & - & - & + \\
\hline & MBC & - & - & - & - & - & + & + \\
\hline \multirow{2}{*}{ Salmonalla enterica } & MIC & - & - & - & - & - & - & + \\
\hline & $\mathrm{MBC}$ & - & - & - & - & - & + & + \\
\hline \multirow{2}{*}{ Bacillus subtilis } & MIC & - & - & - & - & - & - & + \\
\hline & MBC & - & - & - & - & - & + & + \\
\hline
\end{tabular}

Abbreviations: MRSA, methicillin-resistant Staphylococcus aureus, +, microorganism growth; -, without microorganism growth.

Table 3. Synergic Effect of Eucaliptus Oil MIC Plus Silver Nanoparticle MIC Against Escherichia coli O157:H7 ATCC 33150

\begin{tabular}{|c|c|c|c|c|c|}
\hline Strain & MIC/MBC & 25 & 12.5 & 6.25 & 3.12 \\
\hline \multirow{2}{*}{ Escherichia coli 0157: H7 } & MIC & - & - & - & + \\
\hline & MBC & - & - & + & + \\
\hline
\end{tabular}

Abbreviations: +, microorganism growth; -, without microorganism growth.

Financial Disclosure: Authors declared no financial disclosure.

Funding/Support: The current study was financially supported by Islamic Azad University, Iran. 
Table 4. Synergic Effect of Eucaliptus Leaf Oil MIC Plus Silver Nanoparticle MIC Against Escherichia coli PTCC 1399

\begin{tabular}{l|c|c|c|c|c}
\hline \multirow{2}{*}{ Strain } & MIC/MBC & 25 & 12.5 & 6.25 & 3.12 \\
\hline \multirow{2}{*}{ Escherichia coli } & MIC & - & - & - & + \\
\cline { 2 - 6 } & MBC & - & - & + & + \\
\hline
\end{tabular}

Abbreviations: +, microorganism growth; -, without microorganism growth.

Table 5. Synergic Effect of Eucaliptous Leaf Oil MIC Plus Silver Nanoparticle MIC Against Methicillin-resistant Staphylococcus aureus ATCC 33591

\begin{tabular}{l|c|c|c|c|c}
\hline \multirow{2}{*}{ Strain } & MIC/MBC & $\mathbf{2 5}$ & $\mathbf{1 2 . 5}$ & $\mathbf{6 . 2 5}$ & $\mathbf{3 . 1 2}$ \\
\hline \multirow{2}{*}{ MRSA } & MIC & - & - & - & + \\
\cline { 2 - 6 } & MBC & - & - & + & + \\
\hline
\end{tabular}

Abbreviations: MRSA, methicillin-resistant Staphylococcus aureus, +, microorganism growth; -, without microorganism growth.

Table 6. Synergic Effect of Eucaliptous Leaf Oil MIC Plus Silver Nanoparticle MIC Against Salmonella enterica PTCC 1709

\begin{tabular}{l|c|c|c|c|c}
\hline Strain & MIC/MBC & 25 & $\mathbf{1 2 . 5}$ & $\mathbf{6 . 2 5}$ & 3.12 \\
\hline S. enterica & MIC & - & - & - & + \\
\hline & MBC & - & - & + & + \\
\hline
\end{tabular}

Abbreviations: +, microorganism growth; -, without microorganism growth.

Table 7. Synergic Effect of Eucaliptous Leaf Oil MIC Plus Silver Nanoparticle MIC Against Bacillus subtilis PTCC 1156

\begin{tabular}{l|c|c|c|c|c}
\hline Strain & MIC/MBC & $\mathbf{2 5}$ & $\mathbf{1 2 . 5}$ & $\mathbf{6 . 2 5}$ & $\mathbf{3 . 1 2}$ \\
\hline \multirow{2}{*}{ B. subtilis } & MIC & - & - & + & + \\
\cline { 2 - 6 } & MBC & - & + & + & + \\
\hline
\end{tabular}

Abbreviations: +, microorganism growth; -, without microorganism growth.

\section{References}

1. Powers JH. Antimicrobial drug development-the past, the present, and the future. Clin Microbiol Infect. 2004;10 Suppl 4:23-31. doi: 10.1111/j.1465-0691.2004.1007.x. [PubMed: 15522037].

2. Rizzello L, Pompa PP. Nanosilver-based antibacterial drugs and devices: mechanisms, methodological drawbacks, and guidelines. Chem Soc Rev. 2014;43(5):1501-18. doi: 10.1039/c3cs60218d. [PubMed: 24292075].

3. Spellberg B. Dr. William H. Stewart: mistaken or maligned? Clin Infect Dis. 2008;47(2):294. doi: 10.1086/589579. [PubMed: 18564938].

4. Spellberg B, Guidos R, Gilbert D, Bradley J, Boucher HW, Scheld WM, et al. The epidemic of antibiotic-resistant infections: a call to action for the medical community from the Infectious Diseases Society of America. Clin Infect Dis. 2008;46(2):155-64. doi: 10.1086/524891. [PubMed: 18171244].

5. Fauci AS. Infectious diseases: considerations for the 21st century. Clin Infect Dis. 2001;32(5):675-85. doi:10.1086/319235. [PubMed: 11229834].

6. Fauci AS. Emerging and reemerging infectious diseases: the perpetual challenge. Acad Med. 2005;80(12):1079-85. [PubMed:16306276].

7. Morens DM, Folkers GK, Fauci AS. The challenge of emerging and re-emerging infectious diseases. Nature. 2004;430(6996):242-9. doi: 10.1038/nature02759. [PubMed: 15241422].
8. Andersson DI, Hughes D. Antibiotic resistance and its cost: is it possible to reverse resistance? Nat Rev Microbiol. 2010;8(4):260-71. doi: 10.1038/nrmicro2319. [PubMed: 20208551].

9. Levin BR, Rozen DE. Non-inherited antibiotic resistance. Nat Rev Microbiol. 2006;4(7):556-62. doi: 10.1038/nrmicro1445. [PubMed:16778840].

10. Schwaber MJ, De-Medina T, Carmeli Y. Epidemiological interpretation of antibiotic resistance studies - what are we missing? Nat Rev Microbiol. 2004;2(12):979-83. doi: 10.1038/nrmicro1047. [PubMed: 15550943].

11. Levy SB, Marshall B. Antibacterial resistance worldwide: causes, challenges and responses. Nat Med. 2004;10(12 Suppl):S122-9. doi: 10.1038/nm1145. [PubMed: 15577930].

12. Boucher HW. Challenges in anti-infective development in the era of bad bugs, no drugs: a regulatory perspective using the example of bloodstream infection as an indication. Clin Infect Dis. 2010;50 Suppl 1:S4-9. doi: 10.1086/647937. [PubMed: 20067391].

13. Boucher HW, Talbot GH, Bradley JS, Edwards JE, Gilbert D, Rice LB, et al. Bad bugs, no drugs: no ESKAPE! An update from the Infectious Diseases Society of America. Clin Infect Dis. 2009;48(1):1-12. doi: 10.1086/595011. [PubMed: 19035777].

14. Roberts L, Simpson S. Drug resistance. Deadly defiance. Introduction to special issue. Science. 2008;321(5887):355. doi: $10.1126 /$ science.321.5887.355. [PubMed: 18635787].

15. Kresse H, Belsey MJ, Rovini H. The antibacterial drugs market. Nat Rev Drug Discov. 2007;6(1):19-20. doi: 10.1038/nrd2226. [PubMed: 17269159].

16. Projan SJ, Shlaes DM. Antibacterial drug discovery: is it all downhill from here? Clin Microbiol Infect. 2004;10 Suppl 4:18-22. doi: 10.1111/j.1465-0691.2004.1006.x. [PubMed: 15522036].

17. Baker-Austin C, Wright MS, Stepanauskas R, McArthur JV. Co-selection of antibiotic and metal resistance. Trends Microbiol. 2006;14(4):176-82. doi: 10.1016/j.tim.2006.02.006. [PubMed:16537105].

18. Whitesides GM. Nanoscience, nanotechnology, and chemistry. Small. 2005;1(2):172-9. doi: 10.1002/smll.200400130. [PubMed: 17193427].

19. Marambio-Jones C, Hoek EMV. A review of the antibacterial effects of silver nanomaterials and potential implications for human health and the environment. J Nanoparticle Res. 2010;12(5):1531-51. doi: 10.1007/s11051-010-9900-y.

20. Devi LS, Joshi SR. Antimicrobial and synergistic effects of silver nanoparticles synthesized using soil fungi of high altitudes of eastern himalaya. Mycobiology. 2012;40(1):27-34. doi: 10.5941/MYCO.2012.40.1.027. [PubMed: 22783131].

21. Scandorieiro S, de Camargo LC, Lancheros CA, Yamada-Ogatta SF, Nakamura CV, de Oliveira AG, et al. Synergistic and Additive Effect of Oregano Essential Oil and Biological Silver Nanoparticles against Multidrug-Resistant Bacterial Strains. Front Microbiol. 2016;7:760. doi: 10.3389/fmicb.2016.00760. [PubMed: 27242772].

22. Delaquis PJ, Stanich K, Girard B, Mazza G. Antimicrobial activity of individual and mixed fractions of dill, cilantro, coriander and eucalyptus essential oils. Int J Food Microbiol. 2002;74(1-2):101-9. [PubMed: 11929164].

23. Sartorelli P, Marquioreto AD, Amaral-Baroli A, Lima ME, Moreno PR. Chemical composition and antimicrobial activity of the essential oils from two species of Eucalyptus. Phytother Res. 2007;21(3):231-3. doi: 10.1002/ptr.2051. [PubMed: 17154233].

24. O. Oyedeji A, Ekundayo O, Olawore ON, Adeniyi BA, Koenig WA. Antimicrobial activity of the essential oils of five Eucalyptus species growing in Nigeria. Fitoterapia. 1999;70(5):526-8. doi: 10.1016/s0367326x(99)00083-0.

25. Hendry ER, Worthington T, Conway BR, Lambert PA. Antimicrobial efficacy of eucalyptus oil and 1,8-cineole alone and in combination with chlorhexidine digluconate against microorganisms grown in planktonic and biofilm cultures. J Antimicrob Chemother. 2009;64(6):121925. doi: 10.1093/jac/dkp362. [PubMed: 19837714]. 
26. Trivedi NA, Hotchandani SC. A study of the antimicrobial activity of oil of Eucalyptus. Indian J Pharmacol. 2004;36(2):93.

27. CLSI Clinical and Laboratory Standards Institute . Performance standards for antimicrobial disk susceptibility test. Approved standard M02-A10. Wayne: CLSI; 2009.

28. CLSI . Methods for Dilution Antimicrobial Susceptibility Tests f or Bacteria That Grow Aerobically;Approved St andard-Ninth Edition. CLSI document M07-A9. Wayne: Clinical and LaboratoryStandards Institute; 2012.

29. Mirzaei F, Salouti M, Shapouri R, Heidari Z. Antimicrobial effect of plant peptide MBP-1 and silver nanoparticles, along with their synergistic effect on skin infection due to Pseudomonas aeruginosa: in vitro and animal model. Pajoohandeh J. 2013;18(2):64-8.

30. Sharifi-Rad J, Hoseini Alfatemi S, Sharifi Rad M, Iriti M. Antimicrobial Synergic Effect of Allicin and Silver Nanoparticles on Skin Infection Caused by Methicillin-Resistant Staphylococcus aureus spp. Ann Med Health Sci Res. 2014;4(6):863-8. doi:10.4103/2141-9248.144883. [PubMed: 25506477].

31. Naghsh N, Ghiasian M, Soleymani S, Torkan S. Investigation of Eucalyptus and nanosilver as a new nanomixture for growth inhibition of E. coli. Int J Mol Clin Microbiol. 2012;2(1):138-40.

32. Naghsh N, Ghyasiyan M, Soleimani S, Torkan S. Comparison between alcoholic eucalyptus and nano-silver as a new nanocomposition in growth inhibition of Aspergilus niger. Indian J Sci Technol. 2012;5(S3):2445-7.

33. Leid JG, Ditto AJ, Knapp A, Shah PN, Wright BD, Blust R, et al. In vitro antimicrobial studies of silver carbene complexes: activity of free and nanoparticle carbene formulations against clinical isolates of pathogenic bacteria. J Antimicrob Chemother. 2012;67(1):138-48. doi: 10.1093/jac/dkr408. [PubMed: 21972270].

34. Sheikholeslami S, Mousavi SE, Ahmadi Ashtiani HR, Hosseini Doust SR, Mahdi Rezayat S. Antibacterial Activity of Silver Nanoparticles and Their Combination with Zataria multiflora Essential Oil and Methanol Extract. Jundishapur J Microbiol. 2016;9(10):e36070. doi: 10.5812/jjm.36070. [PubMed: 27942360].

35. Narayanan KB, Sakthivel N. Green synthesis of biogenic metal nanoparticles by terrestrial and aquatic phototrophic and heterotrophic eukaryotes and biocompatible agents. Adv Colloid Interface Sci. 2011;169(2):59-79. doi: 10.1016/j.cis.2011.08.004. [PubMed: 21981929].

36. Martinez-Castanon GA, Nino-Martinez N, Martinez-Gutierrez F, Martinez-Mendoza JR, Ruiz F. Synthesis and antibacterial activity of silver nanoparticles with different sizes. J Nanoparticle Res. 2008;10(8):1343-8. doi:10.1007/s11051-008-9428-6.

37. Lara HH, Garza-Trevino EN, Ixtepan-Turrent L, Singh DK. Silver nanoparticles are broad-spectrum bactericidal and virucidal compounds. J Nanobiotechnology. 2011;9:30. doi: 10.1186/1477-3155-9-30. [PubMed: 21812950].

38. Musee N, Thwala M, Nota N. The antibacterial effects of engineered nanomaterials: implications for wastewater treatment plants. $J$ Environ Monit. 2011;13(5):1164-83. doi: 10.1039/c1em10023h. [PubMed: 21505709].

39. Allahverdiyev AM, Abamor ES, Bagirova M, Rafailovich M. Antimicrobial effects of $\mathrm{TiO}(2)$ and $\mathrm{Ag}(2) \mathrm{O}$ nanoparticles against drug-resistant bacteria and leishmania parasites. Future Microbiol. 2011;6(8):933-40. doi: 10.2217/FMB.11.78. [PubMed: 21861623].

40. Guzman M, Dille J, Godet S. Synthesis and antibacterial activity of silver nanoparticles against gram-positive and gram-negative bacteria. Nanomedicine. 2012;8(1):37-45. doi: 10.1016/j.nano.2011.05.007. [PubMed: 21703988].

41. Thill A, Zeyons O, Spalla O, Chauvat F, Rose J, Auffan M, et al Cytotoxicity of $\mathrm{CeO} 2$ nanoparticles for Escherichia coli. Physicochemical insight of the cytotoxicity mechanism. Environ Sci Technol. 2006;40(19):6151-6. [PubMed: 17051814].

42. Soenen SJ, Rivera-Gil P, Montenegro JM, Parak WJ, De Smedt SC, Braeckmans K. Cellular toxicity of inorganic nanoparticles: Common aspects and guidelines for improved nanotoxicity evaluation. Nano Today. 2011;6(5):446-65. doi: 10.1016/j.nantod.2011.08.001.

43. Nel AE, Madler L, Velegol D, Xia T, Hoek EM, Somasundaran P, et al Understanding biophysicochemical interactions at the nano-bio interface. Nat Mater. 2009;8(7):543-57. doi:10.1038/nmat2442. [PubMed: 19525947]. 